\title{
Studies on role of Thyroperoxidase (TPO) Enzyme in Primary Hypothyroidism Affected Dogs
}

\author{
Raguvaran Raja ${ }^{1 *}$, Debabrata Mondal ${ }^{1}$, Jithin Mullakkalparambil Velayudhan ${ }^{2}$, \\ Ravi Shankar Kumar Mandal ${ }^{3}$, Sonam Bhatt ${ }^{4}$, Vivek Joshi ${ }^{1}$ and Umesh Dimri ${ }^{1}$
}

${ }^{1}$ Division of Medicine, ICAR-Indian Veterinary Research Institute, Bareilly, U.P., INDIA

${ }^{2}$ Sardar Vallabhbhai Patel University of Agriculture E Technology, Meerut, U.P., INDIA ${ }^{3} B A S U$, Patna, Bihar, INDIA

${ }^{4}$ National Research Center on Mithun, Nagaland, INDIA

"Corresponding author: R Raja; E-mail: raguivri@gmail.com

\begin{abstract}
The study was aimed to explore the role of auto antibodies against thyroperoxidase (TPO) as a causative factor of primary hypothyroidism in dogs. Dogs presented at Referral Veterinary Polyclinic, Indian Veterinary Research Institute during 2016-17, were screened for hypothyroidism on the basis of clinical signs like lethargy, thickening of skin, bilateral symmetrical alopecia and obesity. Serum and blood samples were collected for biochemical parameters, thyroid profile, TPO concentration and complete blood count. Twenty (20) dogs found positive for hypothyroidism during the study period. Adult dogs aged more than 5 years were commonly affected. Male and female dogs were equally susceptible to hypothyroidism and there was no sexual susceptibility. Clinical pathology revealed significant reduction in $\mathrm{FT}_{4}$ level, altered protein, cholesterol and lipid metabolism in affected dogs. Thyroperoxidase ELISA study showed negligible role of auto-antibodies against TPO as a causative factor of primary hypothyroidism in dogs. All the affected dogs were treated with L-thyroxine (Eltroxin) ${ }^{\circledR} @ 20-40 \mathrm{mcg} / \mathrm{kg}$ bid for life long period along with other symptomatic therapy.
\end{abstract}

\section{HIGHLIGHTS}

(o Primary hypothyroidism is often immune mediated disorder in canine.

(0) Autoantibodies against thyroperoxidase and thyroglobulin play pivotal role in the pathogenesis.

Keywords: Autoimmune, Hypothyroidism, Hypercholesterolemia, Thyroperoxidase

Thyroid gland, bilobed structure located lateral to trachea. Triiodothyronine $\left(\mathrm{T}_{3}\right)$ and L-thyroxine $\left(\mathrm{T}_{4}\right)$ are the important hormones secreted from the gland. Secretion is regulated via negative feedback mechanism through hypothalamic pituitary thyroid axis. Most of the secreted $\mathrm{T}_{4}$ is deiodinated in liver and kidney to form the most potent $\mathrm{T}_{3}$ and $\mathrm{rT}_{3}$. L-thyroxine and triiodothyronine have high affinity towards plasma protein and all the metabolic action is mediated by $\mathrm{T}_{3}$ only. Thyroid hormones interact with nuclear receptor and responsible for various metabolic process in body. Primary hypothyroidism is a common endocrine disorder in dogs (Chastain and Panciera, 1998).
Lymphocytic thyroiditis and idiopathic atrophy are the two most common cause of adult onset of primary hypothyroidism. Lymphocytic thyroiditis occurs because of autoantibodies production against thyroglobulin (TG) (Haines et al., 1984; Mooney, 2011). Histologically, it is characterized by infiltration of gland by lymphocyte, macrophage and plasma cells and end up with follicle destruction and secondary fibrosis. It has similar clinical

How to cite this article: Raja, R., Mondal, D., Velayudhan, J.M., Mandal, R.S.K., Bhatt, S., Joshi, V. and Dimri, U. (2021). Studies on role of Thyroperoxidase (TPO) Enzyme in Primary Hypothyroidism Affected Dogs. J. Anim. Res., 11(05): 909-914.

Source of Support: None; Conflict of Interest: None 
and histologic attributes as that of Hashimoto's thyroiditis in man (Day and Shaw, 2008; Mooney, 2011). Idiopathic atrophy is marked histopathologically by replacement of thyroid parenchyma with adipose tissue. Affected thyroid glands are infiltrated by plasma cells and lymphocytes and there is follicular loss in addition to the presence of autoantibodies specific for thyroglobulin (Tg) and/or triiodothyronine (T3) and thyroxine (T4) in the serum (Nachreiner et al., 2002; Patzl and Mostl, 2003).

Thyroperoxidase, a membrane bound enzyme involved in oxidation of inorganic iodide and transfer of iodide to tyrosine residue of thyroglobulin resulting in formation of monoiodothyrosine (MIT) and diiodothyrosine (DIT). Coupling these molecules result in formation of $\mathrm{T}_{3}$ and $\mathrm{T}_{4}$. Hypothyroidism is associated with decreased concentrations of triiodothyronine $\left(\mathrm{T}_{3}\right)$, thyroxine $\left(\mathrm{T}_{4}\right)$, and increased thyroid stimulating hormone (TSH). These changes lead to increased body weight with altered lipid and glucose metabolism (Diekman et al., 2000; Pucci et al., 2000; Hofer-Inteeworn et al., 2012). Despite of the etiological agents, primary hypothyroidism respond well with supplementation of L-thyroxine @ 0.02-0.04 mg/kg bid preferably in empty stomach. The course of treatment is always lifelong and one can anticipate reappearance of clinical signs after withdrawal of L-thyroxine supplementation. This study deals with role of TPO in auto-immune mechanism of primary hypothyroidism and clinico-pathological changes in affected dogs.

\section{MATERIALS AND METHODS}

Dogs presented at RVP, IVRI during 2016-17, were screened for hypothyroidism on the basis of clinical signs such as lethargy, heat seeking, thickening of skin, bilateral symmetrical alopecia, rat tail appearance and obesity. Serum and blood samples were collected for biochemical parameters, thyroid profile, TPO concentration and complete blood count. Data was analysed by Independent $\mathrm{T}$ test (Two tailed) SPS 16 trail version.

\section{RESULTS AND DISCUSSION}

Twenty (20) dogs found positive for hypothyroidism during the study period. Adult dogs aged more than 5 years was commonly affected (Fig. 1 \& Table 1). Male $(n-10)$ and female (n-10) dogs were equally susceptible to hypothyroidism and there was no sexual susceptibility in this study (Fig. 2). This was in accordance with study of other researchers (Khan CM, 2010). Labrador retriever dogs were highly (n-15) diagnosed with hypothyroidism which may be because of increased adoption of such breed by owners (Fig. 3) in the study region. Clinical examination revealed rat tail appearance with dermatitis (Fig. 4a \& 4b) was the predominant finding in affected dogs. Obesity stands second to rat tail appearance. Some of the presented female dogs had been suffered with infertility problem. Calorigenesis is the earliest recognized effect of thyroid hormone and dogs with hypothyroidism face difficulty in maintaining body temperature (heat seeker). Few dogs in this study reported to have problem in maintaining body temperature. Thickening and puffiness of skin are result of glycosaminoglycans and hyaluronic acid accumulation in dermis (Doliger et al., 1995). Puffiness of skin was evident in only one dog. These clinical signs were in accordance with study of Kour et al. (2021). Hypothyroidism is often associated with secondary skin infection, such as malassezia dermatitis (Maya, 2007; Scott-Moncrieff, 2007). Four $(24 \%)$ dogs were presented with severe dermatitis.

Table 1: Hospital based incidence of hypothyroidism

\begin{tabular}{|c|c|c|}
\hline Age wise incidence & Sex wise incidence & Breed wise incidence \\
\hline$<5$ yrs -17 dogs & Male - 10 & Labrador retriever - 15 \\
\hline \multirow[t]{2}{*}{$>5 \mathrm{yrs}-03 \mathrm{dogs}$} & Female -10 & German shepherd - 3 \\
\hline & & Non descript - 2 \\
\hline
\end{tabular}

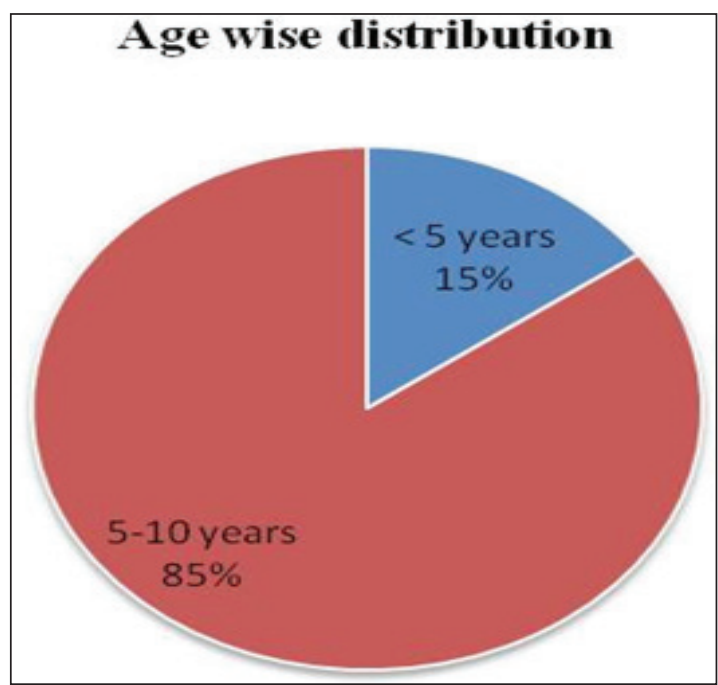

Fig. 1: Age wise distribution of hypothyroidism 


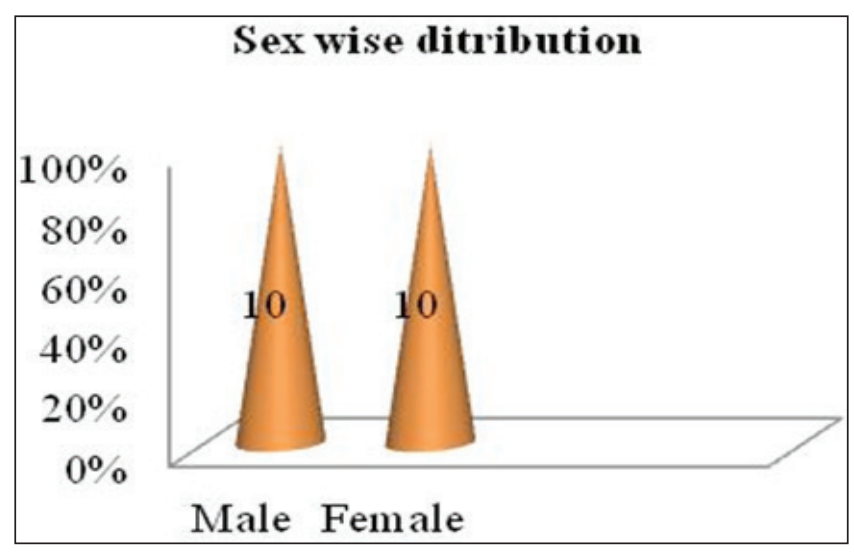

Fig. 2: Sex wise distribution of hypothyroidism

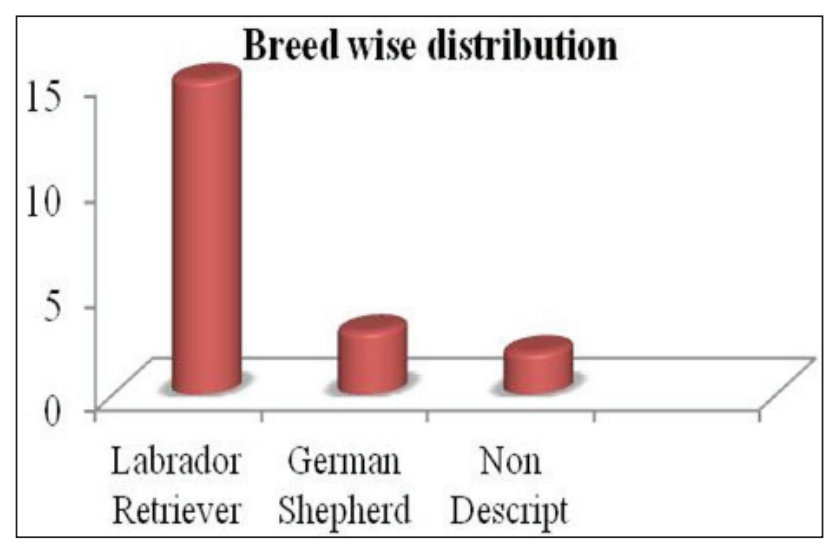

Fig. 3: Breed wise distribution of hypothyroidism

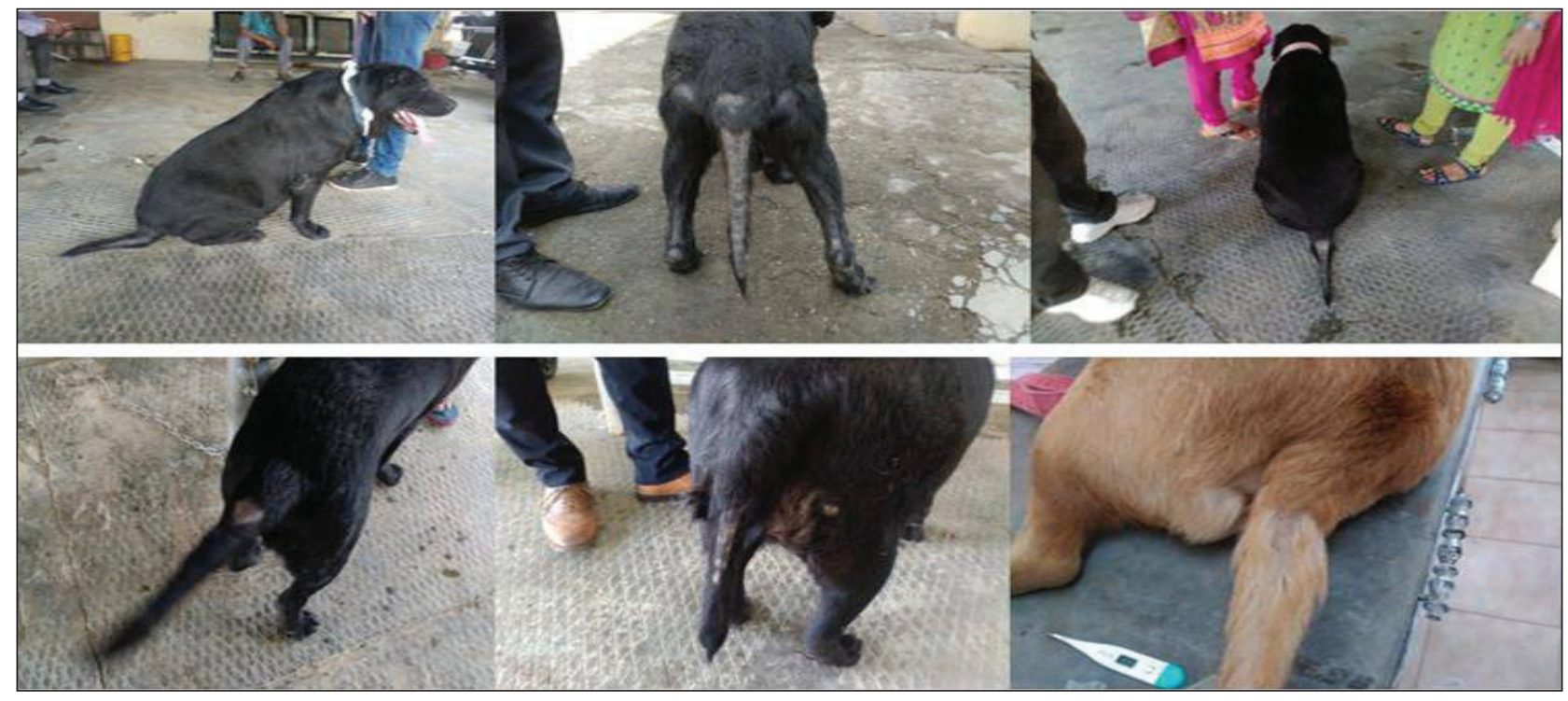

Fig. 4a: Dogs with characteristic rat tail appearance

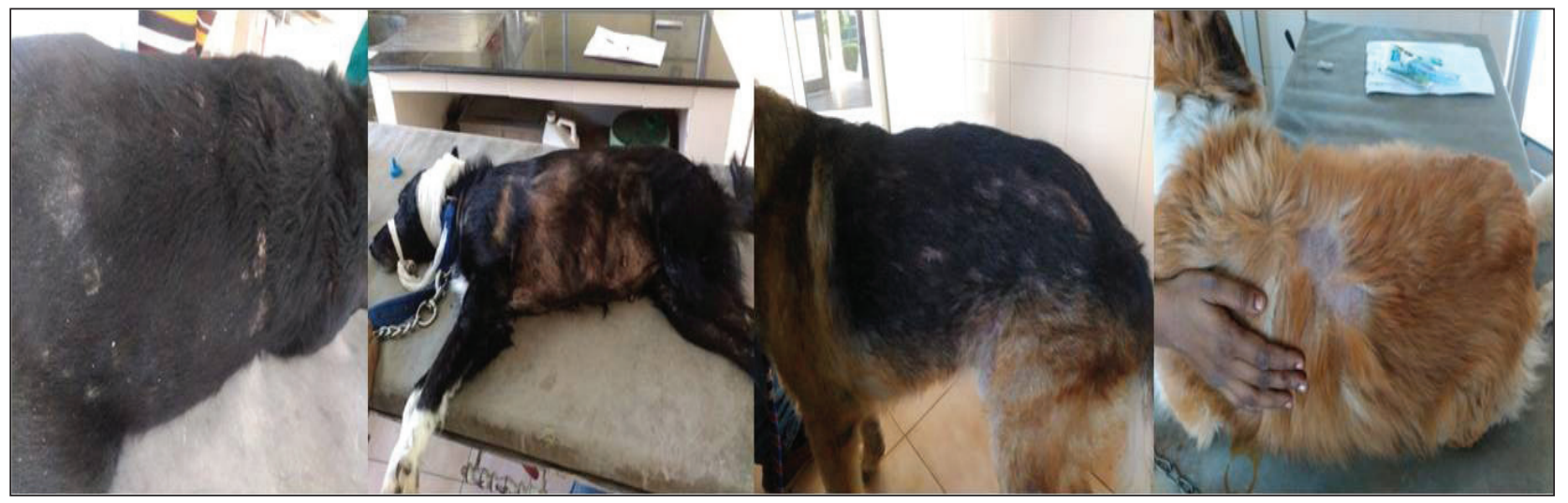

Fig. 4b: Dogs with varying degree of dermatitis 
With respect to thyroid hormone concentration, there was significant $(p<0.05)$ difference between diseased and control group in $\mathrm{FT}_{4}$ concentration. In lymphocytic thyroiditis, thyroglobulin ( $\mathrm{Tg}$ ) in the circulation evokes immune response. It also presents thyroid hormones $\left(\mathrm{T}_{3}, \mathrm{~T}_{4}\right)$ to the immune system (Gaschen et al., 1993). Hence, dogs with lymphocytic thyroiditis have autoantibodies against $\mathrm{Tg}$ and $\mathrm{T}_{4}$ or $\mathrm{T}_{3}$ (Thacker et al., 1992). Dogs with lymphocytic thyroiditis $(91 \%)$ were positive for TGAB. Remarkably $5 \%$ and $6 \%$ dogs with nonthyroidal diseases and healthy dogs were positive for TGAB respectively (Iversen, 1998). Retrospective study on 45,131 canine thyroid hormone results showed $7.9 \%$ prevalence of thyroglobulin antibody (TgAA) in the overall dog population (Nachreiner et al., 2000). TgAApositive results occurred in 10 of 19 hypothyroid, 1 of 28 obese and 1 of 52 clinically healthy dogs. The clinically healthy TgAA-positive dog had additional evidence of hypothyroidism supported by low total T4, low free $\mathrm{T}$ and high canine TSH (Lee et al., 2004)

Autoantibodies against thyroid hormone in hypothyroid dogs tend to interfere with radioimmunoassay determination of $\mathrm{TT}_{4}$ and $\mathrm{TT}_{3}$ (Nachreiner et al., 2002). Estimation of $\mathrm{FT}_{4}$ by equilibrium dialysis method stands accurate for the diagnosis of hypothyroidism as because $\mathrm{FT}_{4}$ is unaffected by thyroid hormone antibodies (Peterson et al., 1997). In addition to that, concurrent treatment with glucocorticoids and acetylsalicylic acid tends to lower $\mathrm{TT}_{4}$ concentration without affecting $\mathrm{FT}_{4}$ (Daminet and Ferguson, 2003; Daminet et al., 2003) TSH-stimulation test using bovine TSH (b-TSH) has been employed often in diagnosis of primary hypothyroidism (Kemppainen et al., 2001). But, gold standard status of TSH-stimulation test is questionable, because TSH values remain within reference range of 20 to $40 \%$ in dogs with confirmed hypothyroidism (Khan, 2010). Falsely high TSH concentration is also observed in euthyroid dogs with nonthyroidal illness (Diaz Espineria et al., 2007). Studies like radionuclide scan, high resolution ultrasonography and thyroid biopsy are most reliable indicator of primary hypothyroidism but, it needs sophisticated instruments and skilled personnel (Resse et al., 2005).

TPO Elisa kit (Ca TPO ELISA, E08T0529, Blue Gene) was procured to study the role of TPO enzyme in autoimmune mechanism. Standard curve was obtained after plotting the OD and concentration of given six standards $(0,5,10$,
$25,50,100)$. Samples were subjected to standard protocol as described in the instruction manual. From the obtained regression equation $\left(y=-67.74 \mathrm{x}+79.87 ; \mathrm{R}^{2}=0.860\right)$ concentrations of TPO in diseased and control group were estimated by incorporating OD values and revealed not much significant difference in comparison to healthy group. Autoantibody against TPO may be associated with primary hypothyroidism in adult animals. Antibodies against TPO play little role in thyroiditis of dogs in contrast to human thyroiditis (Skopek et al., 2006; Graham et al., 2007). Blood and serum biochemical changes in the affected animal have been presented in Table 2. Clinical pathology revealed significant $(\mathrm{p}<0.05)$ reduction in $\mathrm{FT}_{4}$ level, altered cholesterol and lipid metabolism in affected dogs. It was in accord with study of other researchers (Rinjenberk and Kooistra, 2010). Dog with primary hypothyroidism also exhibited multiple metabolic disorders (Raguvaran et al., 2017; Alenka Hrovat et al., 2019). Leptin and insulin concentrations were significantly higher in the hypothyroid compared to normal dogs (Tovi et al., 2010). Increased serum concentrations of adiponectin were recorded in hypothyroid dogs (Tovi et al., 2015). Hyperglobulinemia and hypoalbuminemia were the constant finding in affected dogs. With respect to serum protein concentration, there was significant hypoalbuminemia and hyperglobulinemia in diseased groups. Normocytic, normochromic, nonregenerative anaemia has been the classical finding in hypothyroid dogs. But, there was no significant difference between diseased and control group in complete blood count.

All the affected dogs were treated with L-thyroxine (Eltroxin)®@ $@ 20$ - $40 \mathrm{mcg} / \mathrm{kg}$ bid for life long period. Hypothyroidism is always accompanied by hypercholesterolemia and there is always risk of atherosclerosis. Possible complication of hyperlipidemia is neurological disturbance due to atherosclerosis and thromboembolisms (Hess et al., 2003; Vitale et al., 2007). To avoid such complication, dogs with hypercholesterolaemia were treated with $L$. carnitine (mg/kg b.wt)@150 mg kg b.wt for 30 days along with either atorvastatin@1-2 mg/kg b.wt (dose tapered later) or ezetimibe@0.1-0.2 mg/kg b.wt 30 days. Dogs with secondary bacterial and fungal dermatitis were treated with Tab. Cefadroxil/Cephalexin @10-20 mg/kg b.wt for 3 weeks along with topical antifungal and antibacterial preparation. Advised high protein diet (Chicken, egg 
albumin) along with regular exercise to facilitate fat loss. We also advised the owners to check thyroid profile of their pets annually.

\section{CONCLUSION}

From our study, it was concluded that autoantibody against thyroperoxidase (TPO) plays little or neglible role in primary hypothyroidism of dogs. Bilateral symmetrical alopecia along rat tail appearance was noticed in most of the affected dogs and which may be considered as specific symptoms of hypothyroidism in dog.

\section{ACKNOWLEDGEMENTS}

We acknowledge Director, IVRI for extending financial assistance to run the study. We also acknowledge owners of dogs who had extended their full support during study.

\section{REFERENCES}

Alenka Hrovat, Keuster, T.D., Kooistra, H.S., Duchateau, L., Oyama, M.A., Peremans, K. and Daminet, S. 2019. Behavior in dogs with spontaneous hypothyroidism during treatment with levothyroxine. J. Vet. Intern. Med., 33: 64-71

Beierwaltes, W.H. and Nishiyama, R.H. 1968. Dog thyroiditis: Occurrence and similarity to Hashimoto's struma. Endocrinol., 83: 501-508.

Chastain, C.B and Panciera, D.L. 1998. Hypothyroid diseases. In: Textbook of Veterinary Internal Medicine, Ettinger, S.J. and Feldman, E.C. (eds), $4^{\text {th }}$ Ed. W. B. Saunders Company, Philadelphia, pp. 1487-1500.

Choi, E.W., Shin, I.S., Bhang, D.H., Lee, D.H, Bae, B.K. et al. 2006. Hormonal change and cytokine mRNA expression in peripheral blood mononuclear cells during development of canine autoimmune thyroiditis. Clin. Experim. Immunol., 146: $101-108$

Daminet, S., Croubels, S., Duchateau, L, Debunne, A., Van Geffen, C., Hoybergs, Y., Van bree, H. and De Rick, A. 2003. A influence of acetylsalicylic acid and ketoprofen on canine thyroid function tests. Vet. J., 166: 224-232.

Daminet and Ferguson. 2003. Influence of drugs on thyroid functions in dogs. J. Vet. Inter. Med., pp. 463-472.

Diaz Espineria, M.M., Mol, J.A, Peeters, M.E., Pollakywea Iversen, L., Van Dijk, J.E., Rijnberk, A. and Kooistra, H.S. 2007. Assessment of thyroid function in dogs with low plasma thyroxine concentration. J. Vet. Intern. Med., 21: 2532 .

Diekman, M.J., Anghelescu, N., Endert, E., Bakker, O. and
Wiersinga, W.M. 2000. Changes in plasma low-density lipoprotein (LDL)- and high-density lipoprotein cholesterol in hypo- and hyperthyroid patients are related to changes in free thyroxine, not to polymorphisms in LDL receptor or cholesterol ester transfer protein genes. J. Clin. Endocrinol. Meta., 85: 1857- 1862.

Doliger, S., Delverdier, M., More, J., Longeart, L., Regnier, A. and Magnol, J.P. 1995. Histochemical studies of cutaneous mucins in hypothyroid dogs. Vet. Path., 32: 628-634.

Gaschen, F., Thompson, J., Beale, K. and Keisling, K. 1993. Recognition of triiodothyronine-containing epitopes in canine thyroglobulin by circulating thyroglobulin autoantibodies. Am. J. Vet. Res., 54: 244-247.

Gosselin, S.J., Capen, C.C., Martin, S.L. and Targowski, S.P. 1974. Biochemical and immunological investigations in canine hypothyroidism. Can. J. Comp. Med., 44: 158-168.

Graham, P.A., Refsal, K.R. and Nachreuber, R.F. 2007. Etiopathologic findings of canine hypothyroidism. J. Clin. Small Anim. Pract., 37: 617: 631.

Haines, D.M., Lording, P.M. and Penhale, W.J. 1984. Survey of thyroglobulin autoantibodies in dogs. Am. J. Vet. Res., 45: 1493-1497.

Hess, R.S., Kass, P.H. and Van Winkle, T.J. 2003. Association between diabetes mellitus, hypothyroidism or hypoadrenocorticism and atherosclerosis in dogs. J. Vet. Intern. Med., 17: 489-494.

Hofer-Inteeworn, N., Panciera, D.L., Monroe, W.E., Saker, K., Davies, R.H., Refsal, K.R. and Kemnit, J.W. 2012. Effect of hypothyroidism on insulin sensitivity and glucose tolerance in dogs. Am. J. Vet. Res., 73: 529- 538.

Iversen, L., Jensen, A.L., Høier, R., Skydsgaard, M. and Kristensen, F. 1998. Development and validation of an improved enzyme-linked immunosorbent assay for the detection of thyroglobulin autoantibodies in canine serum samples. Dom. Anim. Endocrinol., 15(6): 525-536.

Kemppainen, R.J. and Behrend, E.N. 2001. Diagnosis of canine hypothyroidism. Perspectives from a testing laboratory. Vet. Clinic. North. Amer. Small. Anim. Pract., 31: 951-962.

Kour, H., Chhabra, S. and Randdawa, C.S. 2021. Clinical and Hematobiochemical Characteristics of Hypothyroidism in Canines. Ind. J. Vet. Sci. Biotech., 17: 1-5.

Khan, C.M. 2010. The Merck Veterinary Manual, $10^{\text {th }}$ Edn., Merck \& CO.,INC, Whitehouse Station, N.J., USA. pp. 505510.

Lee, J.Y., Uzuka, Y., Tanabe, S. and Sarashina, T. 2004. Prevalence of thyroglobulin autoantibodies detected by enzyme-linked immunosorbent assay of canine serum in hypothyroid, obese and healthy dogs in Japan. Res. Vet. Sci., 76: $129-132$. 
Lucke, V.M., Gaskell, C.J. and Wotton, P.R. 1983. Thyroid pathology in canine hypothyroidism. J. Comp. Pat., 93: 415421

Maya, A. 2007. Generalisierete Malassezien- Dermatitis bei einem Deutsche Schaferhund mit hypothyreose-ein fallbericht (Generalized Malassezia dermatitis) in a german shepherd dog with hypothyroidism- a case report. Wien. Tierartzl. Mschr., 94: 169-174.

Mizejewski, G.J., Baron, J. and Poissant, G. 1971. Immunologic investigations of naturally occurring canine thyroiditis. $J$. Immunol., 107: 1152-1160

Mooney, C.T. 2011. Canine hypothyroidism: a review of aetiology and diagnosis. New Zealand Vet. J., 59: 105-114.

Nachreiner, R.F., Bowman, M.M., Graham, P.A., Refsal, K.R. and Provencher Bolliger, A. 2000. The prevalence of thyroglobulin antibody is strongly influenced by breed: a retrospective study of 45.131 canine thyroid diagnostic test results. J. Vet. Int. Med., 14: 232.

Nachreiner, R.F., Refsal, K.R., Graham, P.A. and Bowman, M.M. 2002. Prevalence of serum thyroid hormone autoantibodies in dogs with clinical signs of hypothyroidism. J. Am. Vet. Med. Assoc., 220: 466-471.

Patzl, M. and Mostl, E. 2003. Determination of autoantibodies to thyroglobulin, thyroxine and triiodothyronine in canine serum. J. Vet. Med. A: Physio. Patho. Clin. Med., 50: $72-78$.

Peterson, M.E., Melian, C. and Nichols, R. 1997. Measurement of serum total thyroxine, triiodothyronine, free thyroxine, and thyrotropin concentrations for diagnosis of hypothyroidism in dogs. J. Am. Vet. Med. Assoc., 211: 1396-1402.

Pucci, E., Chiovato, L. and Pinchera, A. 2000. Thyroid and lipid metabolism. Int. J. Obes. Relat. Metab. Disord., 24: 109-
112

Raguvaran, R., Mondal, D.B. and Preena, P. 2017. Clinical Management of Hypothyroidism in a Dog. Intas. Polivet., 18: $153-154$.

Resse, S., Breyer, U., Deeg, C., Kraft, W. and Kaspers, B. 2005. Thyroid sonography as an effective tool to discriminate between euthyroid sick and hypothyroid dogs. J. Vet. Inter. Med., 19: 491-498.

Rinjenberk, A. and Kooistra, H.S. 2010. Clinical Endocrinology of Dogs and Cats, $2^{\text {nd }}$ ed, Schlutersche, Germany, pp. 60-9.

Scott-Moncrieff, J.C. 2007. Clinical signs and concurrent diseases og hypothyroidism in dogs and cats. Vet. Clinic. Small. Anim., 37: 709-722.

Skopek, E., Patzl, M. and Nachreiner, R.F. 2006. Detection of autoantibodies against thyroid peroxidase in serum samples of hypothyroid dogs. Am. J. Vet. Res., 67: 809-814.

Thacker, E.L., Refsal, K.R. and Bull, R.W. 1992. Prevalence of autoantibodies to thyroglobulin, thyroxine, or triiodothyronine and relationship of autoantibodies and serum concentrations of iodothyronines in dogs. Am. J. Vet. Res., 53: 449-453.

Tovi, M.M., Feuermann, Y., Segev, G., Klement, E Yas-Natan, E., Farkas, A., Kol, A. and Shamay, A. 2010. Increased serum leptin and insulin concentrations in canine hypothyroidism. The Vet. J., 183: 109-11.

Tovi, M.M., Sarah, K.A., Kol, A., Farkas, A. and Schenck, P.A. 2015. Increased serum concentrations of adiponectin in canine Hypothyroidism. The Vet. J., 203: 253-255.

Vitale, C.L. and Olby, N.J. 2007. Neurologic dysfunction in hypothyroid, hyperlipidemic Labrador retriever. J. Vet. Intern. Med., 21: 1316-1322. 